\title{
Heat exposure effects among firefighters
}

\section{Abstract}

Background: Firefighting is a hazardous occupation. The firefighters (FF) in extinguishing fire are often exposed to extreme heat of $1200^{\circ} \mathrm{C}$ to $1400^{\circ} \mathrm{C}$ temperature. The heat exposure effects may occur from hot air, radiant heat, contact with hot surfaces, endogenous heat produced by the body during exercise, which cannot be cooled during fire. A significant morbidity and mortality from exposure to heat was reported in other countries but not from India.

Aims: Present study focuses on prevalence of heat exposure effects i.e., heat exhaustion, heat syncope, heat pyrexia and heat cramps recorded among fire fighters of Ahmedabad fire brigade. Settings: Ahmedabad fire brigade (AFB) of Ahmedabad municipal corporation. Design: Cross sectional. Materials and Methods: Present study focuses on prevalence of heat exposure effects i.e., heat exhaustion, heat syncope, heat pyrexia and heat cramps recorded between 262 FF of AFB. This prevalence's were observed among firemen those directly exposed to heat in combating fire and others (load trucks, pump trucks etc.) that assist the firemen. These were seen in different age groups $(<30 ; 31-45$ and $>45 \mathrm{yrs})$, duration of exposure $(<10 ; 11-20$ and $>21 \mathrm{yrs})$. The number of accidents associated with heat exposure was analyzed. Statistical Analysis: Prevalence comparison by Chisquare test. Results: The results revealed that a total of $53(20.0 \%)$ FF reported health exposure effects and were higher among firemen than other groups. Heat exhaustion $48(18.3 \%)$; heat syncope $11(4.2 \%)$; heat pyrexia 11 $(4.2 \%)$ and heat cramps $16(6.1 \%)$ were reported indicating significant occurrence of heat stress among firefighters. In majority of FF, the frequency of occurrence was observed at only one instance. There were no differences according to age or duration of exposure. Among $53 \mathrm{FF}$ with heat exposure effects, accident were reported in 10 $(18.9 \%)$ suggesting that heat stress may be responsible for this. Conclusion: Overall, Significant occurrence of heat exposure effect among FF and wearing cooling jackets/other heat proof materials may be precautionary cum preventive measure.

Key words: Accident duration, firefighters, heat exposure effects

\section{INTRODUCTION}

Fire is the manifestation of rapid combustion or combination of materials with oxygen. Most typically, the word fire refers to the combination of brilliant glow and large amount of heat released during a rapid, self sustaining exothermic process of combustible gases ejected from fuel. The flames are a body of gas that releases heat and light. Whenever there is a fire, the firefighters rush to extinguish it. During this process heat exposure may either be hot dry or water moist type occurs. ${ }^{[1]}$ The heat exposure occurs from hot air, radiant heat, contact with hot surfaces and endogenous heat produced by the body during work.

Firefighters between 1990 and 1995, over 20,000 experienced heat exhaustion or frostbite. Heat turnout gear, SCBA and barrier clothing used for hazardous materials incidents can increase the work of firefighting and impede body temperature control mechanisms further contributing to thermal stress. ${ }^{[2]}$ The description of heat exposure effects are given in details i.e., heat syncope,,$^{[3,4]}$ heat exhaustion, ${ }^{[5,6]}$ heat cramps, $\left.{ }^{[5,7]}\right]$ heat pyrexia $^{[8]}$ and these have been reviewed. ${ }^{[9]}$

Studies on thermal stress in the glass bangle industry, ${ }^{[10]}$ ceramic industry ${ }^{[11]}$ in India were on physiological strain among the workers. A report on physiological responses of firefighters while working in controlled hot environment were assessed using heat rate, body temperature, etc. ${ }^{[12]}$ There are two published reports on studies among firefighters in India ${ }^{[13,14]}$ but none of these above reports evaluated heat exposure effects. Hence in this present study among firefighters, heat exposure morbidity is assessed.
Harshad C. Patel, Nellore Mohan Rao, Asim Saha National Institute of Occupational Health, Ahmedabad, India

For correspondence: Nellore Mohan Rao, Respiratory Physiology Division, National Institute of Occupational Health, Ahmedabad, India. E-mail: dmmohanrao@rediffmail.com

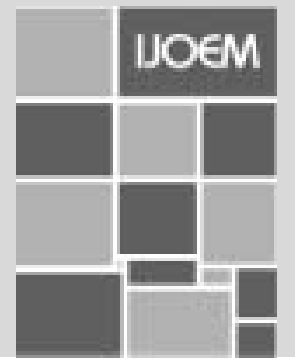




\section{MATERIALS AND METHODS}

A study on health effects among firefighters was conducted among 262 firefighters of Ahmedabad fire brigade (AFB) derived from 11 fire tenders located in different areas of Ahmedabad. This is a part of this study. The firefighters (FF) physical findings, occupational history and heat exposure effects i.e., heat syncope, heat pyrexia, heat cramps, heat exhaustion and heat stroke were recorded in a coded Proforma. The frequency of occurring these effects, their distribution in relation to age $(<30 ; 31-45$ and $>46$ years $)$ and duration of exposure $(<10,11-20$ and $>21$ years $)$ were observed. The number of FF having history of accidents was recorded and among them those associated with heat exposure effects was determined. The relevant results are discussed.

\section{RESULTS}

The details of heat exposure effects i.e., heat cramps, heat exhaustion, heat syncope, heat stroke, heat pyrexia is given in Table 1.

The anthropometric findings of FF that are having heat exposure effects is presented in Table 2. A total of 53 (20.3\%) reported heat exposure effects. Their mean height, weight and BMI is high and deviated much that observed in general

Table 1: Heat exposure effects

\begin{tabular}{ll}
\hline Effects & Details \\
\hline Heat cramps & $\begin{array}{l}\text { This occurs due to salt depletion due to excessive sweating. } \\
\text { These are the first signs that body is having difficulty with } \\
\text { increased temperature }\end{array}$ \\
Heat exhaustion & $\begin{array}{l}\text { It is more serious than heat cramps. It is due to salt and water } \\
\text { depletion occurring due to excessive sweating. This occurs } \\
\text { when a person is exposed to high temperature for a longer } \\
\text { period or the body may become dehydrated and temperature } \\
\text { regulation system may begin to fail. The symptoms include } \\
\text { headache, nausea, exhaustion, weakness, dizziness, faintness, } \\
\text { Heat syncope }\end{array}$ \\
meat stroke & $\begin{array}{l}\text { Due to vasodilatation and excessive sweating, there is } \\
\text { circulatory and vasomotor instability } \\
\text { Under the most extreme conditions, the body temperature } \\
\text { regulate may begin to fail. Subject may become mentally } \\
\text { confused and aggressive, feel paint. There is very little } \\
\text { perspiration. Need emergency medical attention. Without } \\
\text { care, will die in a matter of hours } \\
\text { When the body temperature exceeds } 105^{\circ} \mathrm{C} \text {. It is } \\
\text { chensidered heat pyrexia }\end{array}$ \\
\hline
\end{tabular}

Table 2: Anthropometric findings of fire fighters

\begin{tabular}{lc}
\hline Parameters & Heat exposure $\mathbf{n}=\mathbf{5 3} \mathbf{( 2 0 . 3 )}$ \\
\hline Age $(\mathrm{Yrs})$ & $39.6 \pm 8.6$ \\
Height $(\mathrm{cm})$ & $171.5 \pm 5.4$ \\
Weight $(\mathrm{Kg})$ & $72.9 \pm 10.1$ \\
BMl $\left(\mathrm{Kg} / \mathrm{m}^{2}\right)$ & $24.78 \pm 3.27$ \\
Duration of exposure $(\mathrm{Yrs})$ & $11.74 \pm 7.79$
\end{tabular}

Figures in parentheses indicate percentage, $\mathrm{N}=$ number of fighters population. In Table 3, the distribution of heat exposure effects among $53 \mathrm{FF}$ indicated that majority 48 (90.6\%) had heat exhaustion, followed by heat cramps 16 (30.2\%), heat pyrexia 11 (20.7\%) and heat syncope 5 (9.4\%). This is highly reported among firemen that are directly exposed to fire than the others such as pump trucks, load trucks, etc. The frequency of heat exposure effects showed in Table 4 revealed that majority had one instance.

The association of accidents with that exposure effects presented in Table 5 indicated that out of the total 39 accidents reported by FF, 10 (25.6\%) had an association with heat effects. The age distribution of heat exposure effects given in Table 6 and duration distribution showed in Table 7 did not reveal any significant differences. However, there is a slight increase in prevalence in 31-45 years age compared to $<30$ years age FF.

Table 3: Heat exposure effects among firefighters

\begin{tabular}{lc}
\hline Effect & $\mathbf{N}=\mathbf{5 3}(\mathbf{2 0 . 3 )}$ \\
\hline Heat exhaustion & $48(90.6)$ \\
Heat syncope & $05(9.4)$ \\
Heat pyrexia & $11(20.7)$ \\
Heat cramps & $16(30.2)$ \\
Fire men & $40(75.5)$ \\
Others & $13(24.5)$ \\
\hline
\end{tabular}

Figures in parenthesis indicate percentage, $\mathrm{N}=$ number of fighters

Table 4: Frequency of heat exposure effects

\begin{tabular}{lcccc}
\hline Frequency & $\begin{array}{c}\text { Heat } \\
\text { exhaustion } \\
\mathbf{N}=\mathbf{4 8}\end{array}$ & $\begin{array}{c}\text { Heat } \\
\text { syncope } \\
\mathbf{N = 5}\end{array}$ & $\begin{array}{c}\text { Heat } \\
\text { pyrexia } \\
\mathbf{N = 1 1}\end{array}$ & $\begin{array}{c}\text { Heat } \\
\text { cramps } \\
\mathbf{N}=\mathbf{1 6}\end{array}$ \\
\hline 1 time & $39(81.2)$ & $03(60.0)$ & $10(90.9)$ & $15(93.8)$ \\
2 time & $06(12.5)$ & Nil & Nil & Nil \\
3 time & $01(2.1)$ & $01(20.0)$ & Nil & Nil \\
$\geq 4$ times & $02(4.2)$ & $01(20.0)$ & $01(9.1)$ & $01(6.2)$ \\
\hline
\end{tabular}

Figures in parentheses indicate percentage, $\mathrm{N}=$ number of fighters

Table 5: Association of accident with heat exposure effects

\begin{tabular}{ll}
\hline Information & $\mathbf{N}=\mathbf{3 9}$ \\
\hline Accidents with heat exposure symptoms & $10(25.6)$ \\
\hline
\end{tabular}

Figures in parentheses indicate percentage, $\mathrm{N}=$ number of fighters

Table 6: Age distribution of heat exposure morbidity fire fighters

\begin{tabular}{lccc}
\hline Group & \multicolumn{3}{c}{ Age groups (Yrs) } \\
\cline { 2 - 4 } & $<\mathbf{3 0} \mathbf{N = 5 2}$ & $\mathbf{3 1 - 4 5 ~} \mathbf{N}=114$ & $\mathbf{4 6 + N = 0 6}$ \\
\hline Heat exposure FF $\mathrm{N}=53$ & $10(19.2)$ & $24(29.8)$ & $19(19.8)$ \\
\hline
\end{tabular}

Table 7: Duration of exposure and heat exposure morbidity among firefighters

\begin{tabular}{lccc}
\hline Morbidity & \multicolumn{3}{c}{ Duration of exposure (Yrs) } \\
\cline { 2 - 4 } & $<\mathbf{1 0} \mathbf{N}=\mathbf{1 5 0}$ & $\mathbf{1 1 - 2 0 ~} \mathbf{N = 5 3}$ & $\mathbf{2 1} \mathbf{N = 5 9}$ \\
\hline Heat exposure effects & $29(19.3)$ & $11(20.8)$ & $13(22.0)$ \\
\hline
\end{tabular}




\section{DISCUSSION}

Most fatalities from fires are not due to burns, but are a result of inhalation of toxic gas, produced during combustion. Fire produces a complex toxic environment involving flame, heat, oxygen depletion, smoke and toxic gases. ${ }^{[15]}$ The present findings on heat exposure effects produced significant morbidity predominantly heat exhaustion, followed by heat cramps, heat pyrexia etc. The firemen that directly deal with fire reported higher prevalence indicating occupational thermal stress among this group. These effects are irrespective of age and duration. An interesting finding is the occurrence of accidents 10 (25.6\%) of the total accidents associated with heat exposure suggest that the psychological effects associated with heat exposure may be responsible for this. The author knows an example of this in a case of accident due to severe heat exposure went into coma stage and was in hospital for a duration of 19 years and later succumbed to death.

To guard against heat stress and other medical emergencies at the fire scene, provide cool water supplies, rest areas and other access to emergency medical personnel. ${ }^{[16]}$ Wearing cooling Jackets/other heatproof materials may be precautionary cum preventive measure to protect from heat exposure effects.

More studies are needed on health evaluation among firefighters in India.

\section{ACKNOWLEDGEMENT}

The authors are thankful to Dr. HN Saiyed, Director, NIOH for granting permission for presentation at $56^{\text {th }}$ National Conference of IAOH held at Jamshedpur during 10-12 February 2006 and publishing it. Authors express their sincere gratitude to Shri Arun Patel, Statistical Assistant, Shri Atul Shah, Technician, Shri MD Patel for their technical assistance during the course of this study. Sincere thanks to Shri Bipin Jadeja, Chief of Ahmedabad Fire Brigade and other officers that extended cooperation during the course of this study.

\section{REFERENCES}

1. Bag SP. Occupational hazards in fire service profession - Technical papers presented at Firetech India: Panaji, Goa; $200312^{\text {th }}-14^{\text {th }}$ Feb.

2. National Fire Protection Association, MA, NEFA 1996 as quoted by Branhardsand and Pappas G.P. Chapter 110. Firefighters Health and Safety Text Book of Environmental and Occupational Medicine. $3^{\text {rd }}$ ed. Rom WN, editor. Lippincott: Raven; 1998. p. 1457.

3. Wyndham CH, Benade AJ, Williams CG, Strydom NB, Goldin A, Heyns AJ. Changes in central circulation and body fluid spaces during acclimatization to heat. J Appl Physiol 1968;25:586-93.

4. Shvartz E, Styrdom NB, Kolze H. Orthostatism and heat acclimation. J Appl Physiol 1975;39:590-5.

5. Knochel JP. Environmental heat illness: An electric review. Arch Intern Med 1974;133:841-64.

6. Costrine AM, Pills MA, Gustafson AB, Uddin DE. Cardiovascular and metabolic manifestations of heat stroke and severe heat exhaution. Am J Med 1979;66:296-302.

7. Talbolt JH. Heat cramps. Medicine 1965;14:323-76.

8. Gold J. Development of heat pyrexia. JAMA 1960;173:1175-82.

9. Delamy KA, Goldfrank LR. Chapter 104: Hot and cold work environment - Text book of environmental and occupational medicine. $3^{\text {rd }}$ ed. Rom WN, editor. Lipincott: Raven; 1998. p. 1389-410.

10. Rathod RA, Bhagia LJ, Pandya GL, Katagade VL, Parikh DJ, Chatterjee BB. Thermal stress and physiological strain in the glass bangle industry. Eur J Appl Physiol Occup Physiol 1987;56:58-63.

11. Parikh DJ, Ghodasara NB, Ramanathan NL. A special thermal stress problem in ceramic industry. Eur J Appl Physiol Occup Physiol 1978;40:63-72.

12. Richardson JE, Capra MF. Physiological responses of firefighters wearing level 3 chemical protective suits while working in controlled hot environments. J Occup Environ Med 2001;43:1064-72.

13. Joshi TK, Kishore J. Comparing health status of Delhi Fire Service Workers and Village population. Indian J Occup Environ Med 1998;2:84-7.

14. Chattopadhyay BP, Gangopadhyay PK, Alam J, Roychowdhury A. Effect of exposure on respiratory function status of firefighters in an accidental fire in a chemical warehouse. Indian J Occup Environ Med 2004;8:19-25.

15. Stefanidou M, Athanaselis S. Toxicological aspects of fire. Vet Hum Toxicol 2004;46:196-9.

16. Health hazard evaluations: Issues related to occupational exposure to firefighters 1990 to 2001. Department of Health and Human Services. Centres for Disease Control and Prevention. National Institute of Occupational Safety and Health (NIOSH): January 2004.

Source of Support: Nil, Conflict of Interest: None declared.

\section{Author Help: Choosing an appropriate category of article for faster publication}

The manuscript system (www.journalonweb.com) allows the authors to check a likely publication date for a newly submitted article. Based on number of articles in review, number of accepted articles and acceptance rate, the system estimates the likely publication date for an article submitted on a given date.

If there are too many articles in a category e.g., case report, a newly submitted case report if accepted may have to wait for a long period before publication. Hence, the author can check other categories e.g. letter to editor or images, for such paper and submit to another category of articles. 